\title{
Optimisation of solid-phase microextraction combined with gas chromatography-mass spectrometry based methodology to establish the global volatile signature in pulp and skin of Vitis vinifera L. grape varieties
}

\author{
Rosa Perestrelo ${ }^{\mathrm{a}, \mathrm{b}}$, António S. Barros ${ }^{\mathrm{b}}$, Sílvia M. Rocha ${ }^{\mathrm{b}}$, José S. Câmara ${ }^{\mathrm{a}, *}$

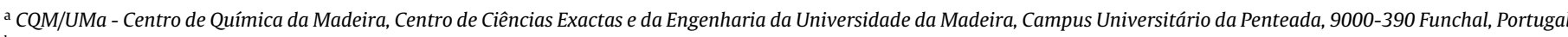

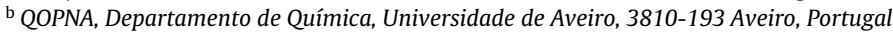

\section{A R T I C L E I N F O}

\section{Article history:}

Received 22 December 2010

Received in revised form 19 May 2011

Accepted 11 June 2011

Available online 29 June 2011

\section{Keywords:}

Vitis vinifera L. grapes

Pulp

Skin

HS-SPME/GC-qMS

PCA

Volatile signature

\begin{abstract}
A B S T R A C T
The volatiles (VOCs) and semi-volatile organic compounds (SVOCs) responsible for aroma are mainly present in skin of grape varieties. Thus, the present investigation is directed towards the optimisation of a solvent free methodology based on headspace-solid-phase microextraction (HS-SPME) combined with gas chromatography-quadrupole mass spectrometry (GC-qMS) in order to establish the global volatile composition in pulp and skin of Bual and Bastardo Vitis vinifera L. varieties. A deep study on the extraction-influencing parameters was performed, and the best results, expressed as GC peak area, number of identified compounds and reproducibility, were obtained using $4 \mathrm{~g}$ of sample homogenised in $5 \mathrm{~mL}$ of ultra-pure Milli-Q water in a $20 \mathrm{~mL}$ glass vial with addition of $2 \mathrm{~g}$ of sodium chloride $(\mathrm{NaCl})$. A divinylbenzene/carboxen/polydimethylsiloxane fibre was selected for extraction at $60^{\circ} \mathrm{C}$ for $45 \mathrm{~min}$ under continuous stirring at $800 \mathrm{rpm}$. More than 100 VOCs and SVOCs, including 27 monoterpenoids, 27 sesquiterpenoids, 21 carbonyl compounds, 17 alcohols (from which 2 aromatics), $10 C_{13}$ norisoprenoids and 5 acids were identified. The results showed that, for both grape varieties, the levels and number of volatiles in skin were considerably higher than those observed in pulp. According to the data obtained by principal component analysis (PCA), the establishment of the global volatile signature of grape and the relationship between different part of grapes-pulp and skin, may be an useful tool to winemaker decision to define the vinification procedures that improves the organoleptic characteristics of the corresponding wines and consequently contributed to an economic valorization and consumer acceptance.
\end{abstract}

(c) 2011 Elsevier B.V. All rights reserved.

\section{Introduction}

The volatile composition of grapes is one of the most important factors determining wine character and quality $[1,2]$. As in many food products, grape and wine aroma is influenced by the action of hundreds of VOCs and SVOCs belonging to different chemical groups, namely mono and sesquiterpenoids, $\mathrm{C}_{13}$ norisoprenoids, alcohols, acids, carbonyl compounds, sulphur compounds, pyrazines, among others [3-5]. They have a considerable influence on the sensorial complexity of grapes, and consequently of juices and wines covering a wide range of polarities, volatilities, and concentrations. They result from several biochemical and technological processes that originally arises from grapes, and are considerably influenced by several factors, like grape variety, culture practices, climate, soil type, and geographical location [6,7].

\footnotetext{
* Corresponding author. Tel.: +351 291705112; fax: +351291705149

E-mail address: jsc@uma.pt (J.S. Câmara).
}

These compounds, which are secondary products of the plant metabolism, were found to be distributed through the different parts of the berry, namely pulp and skin, which depend on the variety. Several studies show that these compounds were found predominantly in skin tissue and typically stored as sugar or amino acid conjugates in the vacuoles of the exocarp cells [3]. Bayonove et al. [8] observed a highly uneven distribution of some free monoterpenes in different fractions of Muscat grapes. Geraniol and nerol, for example, were associated primarily with the skins of the berries, whereas linalool was more uniformly distributed between the juice and skin. Similar results were also obtained by Cordonnier and Bayonove [9], where linalool was equally distributed between juice and skin, whereas $95 \%$ of geraniol and nerol were found in skin of Muscat of Alexandria grapes. The intensity and quality of wine aroma might be influenced by different skin contact times $[10,11]$. However, an exhaustive time of contact could induce an unpleasant effect due to the extraction of $C_{6}$ alcohols responsible for the undesirable herbaceous aromas. Thus the knowledge of the volatile and semi-volatile composition of grapes, including their distribution between pulp and skin, offers a mean for evaluating 
the potential aroma of a grape variety, allowing the improvement of the quality of wine aroma.

Many of the volatiles (VOCs) and semi-volatile organic compounds (SVOCs) of grapes are generally present in trace amounts (from several $\mathrm{mg} \mathrm{L}^{-1}$ to a few $\mathrm{ng} \mathrm{L}^{-1}$, or even less), which means that an effective extraction technique (enrichment or focusing), as well as a sensitive methodology of analysis are required to proper characterize them. Previously, several methodologies involving solvent extraction (pentane/diethyl ether, dichloromethane, ethyl acetate) [12], simultaneous distillation-extraction (SDE) [13] or concentration on solid-phase supports (solid-phase extraction-SPE) [14,15] followed by analysis using gas chromatography-mass spectrometry (GC-MS), have been widely proposed and used to establish the aroma profile of grapes and wines. Nevertheless, these conventional enrichment methodologies have some important drawbacks, such as their relatively low reproducibility, low selectivity, and loss of analytes during the concentration steps. Additionally, they require the use of toxic and expensive solvents, are timeconsuming, and labour-intensive.

More recently, solvent free methodologies that overcome these drawbacks have been developed, such as solid-phase microextraction (SPME) and stir bar sorptive extraction (SBSE). SPME methodology provides a suitable tool for organic analytical chemistry because is a fast, simple and sensitive procedure which offers important advantages as it eliminates the use of organic solvents and allows to combine sampling, extraction and concentration into a single step, and substantially shortening analysis time [16]. For these reasons, SPME applications in food analysis are vast, and recently have been successfully applied to study the volatile composition of grapes [3,17-22], and wines [23-25]. Nevertheless, in these studies few extraction-influencing parameters were taken into account. For example, only two SPME fibre coatings, at two extraction times ( 30 and $60 \mathrm{~min}$ ) and two temperatures (40 and $50^{\circ} \mathrm{C}$ ) have been used for the optimisation of HS-SPME methodology to profile the volatile composition in Cabernet Sauvignon grapes by Canuti et al. [3]. In order to obtain a reliable methodology to study grape VOCs and SVOCs, Sánchez-Palomo et al. [20] tested three fibre coatings, and different extraction times (10, 20, 30, 40 and $50 \mathrm{~min}$ ) and temperatures $\left(40,50,60\right.$ and $\left.70^{\circ} \mathrm{C}\right)$, while Kalua and Boss [19] focused their study on the grapes dilution solvent, and sample/headspace volume optimisation.

As, VOCs and SVOCs are mainly present in skin of grape varieties, the current investigation is directed towards the development of a reliable and solvent free HS-SPME/GC-qMS methodology to establish the global volatile signature in pulp and skin of Bual and Bastardo Vitis vinifera L. grape varieties. In order to improve the extraction efficiency, the conducted research involves a deep study on extraction-influencing parameters, such as fibre coating, extraction time, extraction temperature, ionic strength, sample amount (ratio $1 / \beta$ ), and sample dilution. Finally, principal component analysis (PCA) was applied in order to characterize the pulp and skin of Bual and Bastardo grape varieties as a function of the chemical groups identified by HS-SPME/GC-qMS methodology.

\section{Materials and methods}

\subsection{Reagents and materials}

All chemicals were analytical quality. Sodium chloride (99.5\%) and ethanol (99.9\%) were supplied from Panreac (Spain, Barcelone) and Merck (Dramstadt, Germany), respectively. Standards of VOCs and SVOCs used for identification of target compounds were purchased from Sigma-Aldrich (Madrid, Spain), Acros Organics (Geel, Belgium), and Fluka (Buchs, Switzerland) with purity $>98 \%$. The individual stock solutions were prepared in ethanol at concen- tration of $1000 \mathrm{mg} \mathrm{L}^{-1}$, and stored at $4^{\circ} \mathrm{C}$. Ultra-pure water from Milli-Q system (Millipore, Bedford, USA) with conductivity of $18 \mathrm{M} \Omega$ was used throughout. Helium of purity 5.0 (Air Liquid, Portugal) was utilized as the GC carrier gas. The glass vials, SPME fibres, and SPME holder for manual sampling were purchased from Supelco (Bellenfonte, PA, USA). The retention index (RI) was calculated through injection of a series of $C_{8}$ to $C_{20}$ straight-chain $n$-alkanes (concentration of $40 \mathrm{mg} \mathrm{L}^{-1}$ in $n$-hexane) supplied from Fluka (Buchs, Switzerland).

\subsection{Samples}

Healthy mature-state Vitis vinifera L. Bual (white) and Bastardo (red) grapes, from the 2008 harvest were collected at maturity state based on sugar/acid ratio, in Região Autónoma da Madeira Appellation (RAM), Portugal, from an experimental vineyard (Quinta das Vinhas, Estreito da Calheta) operated by the Regional Secretary of Agriculture. For each sampling, $400 \mathrm{~g}$ of grapes were picked randomly throughout the vine, taking into consideration the number of berries per bunch and the balance between shadow, and sun exposure in the different vineyard locations, following a z-shaped pattern to avoid edge and centre effects. Samples were transported immediately under refrigeration $\left(\mathrm{ca} .2-5^{\circ} \mathrm{C}\right.$ ) to the laboratory, and stored at $-20^{\circ} \mathrm{C}$ until analysis.

\subsection{HS-SPME procedure}

The grapes were manually pealed and the skins were separated from the pulp. Both fractions (skin and pulp) were individually homogenised and analysed. The pulp of Bual grapes was selected as the matrix for the optimisation of SPME extraction-influencing parameters. For headspace sampling, aliquots of $4 \mathrm{~g}$ of sample (pulp and skin, respectively) were placed into a $20 \mathrm{~mL}$ glass vial, containing $2 \mathrm{~g}$ of sodium chloride $(\mathrm{NaCl})$ and $5 \mathrm{~mL}$ of ultra-pure Milli-Q water, which correspond to a ratio of the volume of the liquid phase to the headspace volume $(1 / \beta)$ of 0.5 . After addition of a stirring bar $(2 \mathrm{~mm} \times 0.5 \mathrm{~mm}$, for stirring at $800 \mathrm{rpm})$, the vial was closed, and placed in a thermostatted bath adjusted to $60 \pm 1^{\circ} \mathrm{C}$. After this step the SPME fibre was manually inserted into the sample vial headspace during $45 \mathrm{~min}$. After conclusion of extraction process, the fibre was retracted prior to remove from the sample vial and immediately inserted into the injection port of the GC for desorption at $250^{\circ} \mathrm{C}$ for $7 \mathrm{~min}$ in splitless mode ( $5 \mathrm{~min}$ ). All measurements were made with, at least, three replicates.

\subsection{Optimisation of SPME parameters}

To optimise the SPME extraction efficiency, some experimental parameters, namely fibre coating, extraction time and temperature, ionic strength, sample amount (ratio $1 / \beta$ ), and sample dilution, were taken into account.

\subsubsection{Selection of the fibre coating}

The selection of the fibre coating was carried out by testing six types of commercially available silica SPME fibres, varying in polarity, thickness of the stationary phase, and coated with the following polymers: polydimethylsiloxane (PDMS, $100 \mu \mathrm{m}$ ), polydimethylsiloxane/divinylbenzene (PDMS/DVB, $65 \mu \mathrm{m}$ ), divinylbenzene/carboxen/polydimethylsiloxane (DVB/CAR/PDMS, $50 / 30 \mu \mathrm{m})$, carboxen/polydimethylsiloxane (CAR/PDMS, $75 \mu \mathrm{m}$ ), polyacrylate (PA, $85 \mu \mathrm{m}$ ), and carbowax/divinylbenzene (CW/DVB, $70 \mu \mathrm{m})$.

Fibres were thermally conditioned in accordance with the manufacture's recommendations before first use. Before the first daily analysis, the fibres were conditioned for $15 \mathrm{~min}$ at $250^{\circ} \mathrm{C}$. The SPME procedure described above (Section 2.3) was used to select the fibre 
coating. A blank test was performed to check possible carry-over. At least three replicates were done for each fibre.

\subsubsection{Effect of extraction time and temperature}

Extraction time and temperature are two of the most important parameters affecting the volatility and solubility of analytes. Therefore, these two parameters were optimised. The procedure described in Section 2.3 was employed to evaluate the extraction time and temperature. The HS-SPME extraction of the real samples (pulp from Bual grapes) was done using fibre exposition times between 15 and 60 min using DVB/CAR/PDMS fibre at $40^{\circ} \mathrm{C}$ under constant stirring $(800 \mathrm{rpm})$. In order to optimise the extraction temperature, up to three consecutive extractions were carried out at each of the following temperatures 30,40 and $60^{\circ} \mathrm{C}$ using DVB/CAR/PDMS fibre during 45 min under constant stirring (800 rpm).

\subsubsection{Effect of ionic strength, sample dilution, and sample/headspace volume}

Since the addition of a saturating amount of salt is reported to improve fibre extraction efficiency, three different amounts of sodium chloride $(1,2$, and $3 \mathrm{~g}$ ) were evaluated. Sample dilution ( $2 \mathrm{~g}$ of pulp sample diluted in 2.5, 5 and $10 \mathrm{~mL}$ of ultra-pure Milli$\mathrm{Q}$ water), and sample amount (1,2 and $4 \mathrm{~g}$ of sample in a $20 \mathrm{~mL}$ glass vial) were investigated for their effect on the partitioning of analytes between the sample. All measurements were performed in triplicate with DVB/CAR/PDMS fibre at $60^{\circ} \mathrm{C}$ for $45 \mathrm{~min}$ under constant stirring (800 rpm).

\subsection{GC-qMS conditions}

The SPME coating fibre containing VOCs and SVOCs of pulp and skin was manually introduced into the GC injection port at $250^{\circ} \mathrm{C}$ (equipped with a glass liner, $0.75 \mathrm{~mm}$ I.D.) and kept for $7 \mathrm{~min}$ for desorption. The desorbed VOCs and SVOCs were separated in a Agilent Technologies 6890N Network gas chromatography equipped with a BP-20 fused silica capillary column $(30 \mathrm{~m} \times 0.25 \mathrm{~mm}$ I.D. $\times 0.25 \mu \mathrm{m}$ film thickness $)$ supplied by SGE (Darmstadt, Germany) connected to an Agilent 5973N quadrupole mass selective detector. Helium (Air Liquid, Portugal) was used as the carrier gas at a flow rate of $1.2 \mathrm{~mL} \mathrm{~min}^{-1}$ (column-head pressure: $12 \mathrm{psi}$ ). The injections were performed in the splitless mode ( $5 \mathrm{~min}$ ). The GC oven temperature was programmed as follows: held at $40^{\circ} \mathrm{C}$ for $5 \mathrm{~min}$ then ramped at $2^{\circ} \mathrm{C} \mathrm{min}^{-1}$ to $220^{\circ} \mathrm{C}$, and held there for $20 \mathrm{~min}$. For the MS system, the temperatures of the transfer line, quadrupole and ionization source were 250, 150 and $230^{\circ} \mathrm{C}$, respectively; electron impact mass spectra were recorded at $70 \mathrm{eV}$ and the ionization current was about $30 \mu \mathrm{A}$. The acquisitions were performed in full scan mode $(30-300 \mathrm{~m} / \mathrm{z})$. The GC peak area of each compound was obtained from the ion extraction chromatogram (IEC) by selecting target ions for each one. Reproducibility was expressed as relative standard deviation (RSD). Signal acquisition and data processing were performed using the HP Chemstation (Agilent Technologies).

Identification of VOCs and SVOCs was achieved (1) comparing the GC retention times and mass spectra, with those, when available, of the pure standard compounds, (2) all mass spectra were also compared with the data system library (NIST, 2005 software, Mass Spectral Search Program V.2.0d; NIST 2005, Washington, DC), and (3) Kovats retention index (RI) value were determined according to the Van den Dool and Kratz [26]. For the determination of the RI, a $\mathrm{C}_{8}-\mathrm{C}_{20} n$-alkanes series was used, and the values were compared, when available, with values reported in the literature for similar chromatographic columns [27-55].

\subsection{Statistical analysis}

PCA was applied to the auto-scaled areas of the 107 VOCs and SVOCs identified in pulp and skin of Bual and Bastardo by HSSPME/GC-qMS, each with three independent replicates, using $R$ statistical software package [56]. The goal was to extract the main sources of variability and hence to help on the characterisation of the dataset [57].

\section{Results and discussion}

The effectiveness of SPME extraction depends on several experimental parameters, such as fibre coating, extraction time and temperature, ionic strength, sample dilution, and sample amount (ratio $1 / \beta$ ). The best conditions obtained for HS-SPME/GC-qMS methodology was chosen based on intensity response (GC peak area), number of identified compounds, and relative standard deviation (RSD \%). After the optimisation step, the global volatile signature of the pulp and skin from Bual and Bastardo grapes was established.

\subsection{Performance of HS-SPME/GC-MS methodology}

\subsubsection{Selection of the fibre coating}

The selection of a suitable fibre coating is an important step in SPME optimisation. The extraction efficiency of SPME depends greatly on the value of the distribution constant of analytes partitioned between the sample and the fibre coating material. Thus, six fibres commercially available were tested.

According to Fig. 1a, the extraction efficiency of DVB/CAR/PDMS, expressed as GC peak area, to carbonyl compounds (CC), alcohols (ALC) and monoterpenoids (MONOT) was higher than the other fibres under study, while the PDMS/DVB had a higher extraction capacity for $\mathrm{C}_{13}$ norisoprenoids (NORIS), and CW/DVB for acids (Fig. 1a). The carboxen fibres (DVB/CAR/PDMS, CAR/PDMS) showed similar extraction efficiency for monoterpenoids and $\mathrm{C}_{13}$ norisoprenoids (Fig. 1a). The results of this screening showed that the highest GC peak areas were obtained for the carboxen-related stationary phase (Fig. 1b). However, considering the number of compounds identified, the best performance was achieved by DVB/CAR/PDMS (46 compounds) and PDMS/DVB (46), followed by CW/DVB (33), CAR/PMDS (25), PA (22), and PDMS (19). DVB/CAR/PDMS coating (molecular weight ranging from 40 to 275) combines the absorption properties of the liquid polymer with the adsorption properties of porous particles, which contains macro (>500 $\AA$ ), meso $(20-500 \AA)$ and microporous (2-20 $)$ and has bipolar properties. The mutually synergetic effect of adsorption and absorption of the stationary phase explains its high retention capacity.

DVB/CAR/PDMS fibre was selected for all further optimisation steps, and pulp and skin analysis.

\subsubsection{Extraction time and temperature}

To extraction time optimisation, DVB/CAR/PDMS fibre was exposed into the headspace between 15 and $60 \mathrm{~min}$. The influence of the extraction time on the extraction efficiency, towards the chemical groups under study, is presented in Fig. 2a. The best extraction efficiency was obtained for 45 and $60 \mathrm{~min}$. For both times, similar total GC peak areas, RSD and number of identified compounds were observed. Thus, in order to implement a more expeditious methodology, the lower extraction time was selected (45 min).

The extraction temperature presents several effects on extraction efficiency. The temperature increases diffusion coefficients and Henry's constants, while, the time required to reach equilibrium decreases $[20,58]$. To check the effect of temperature on SPME 


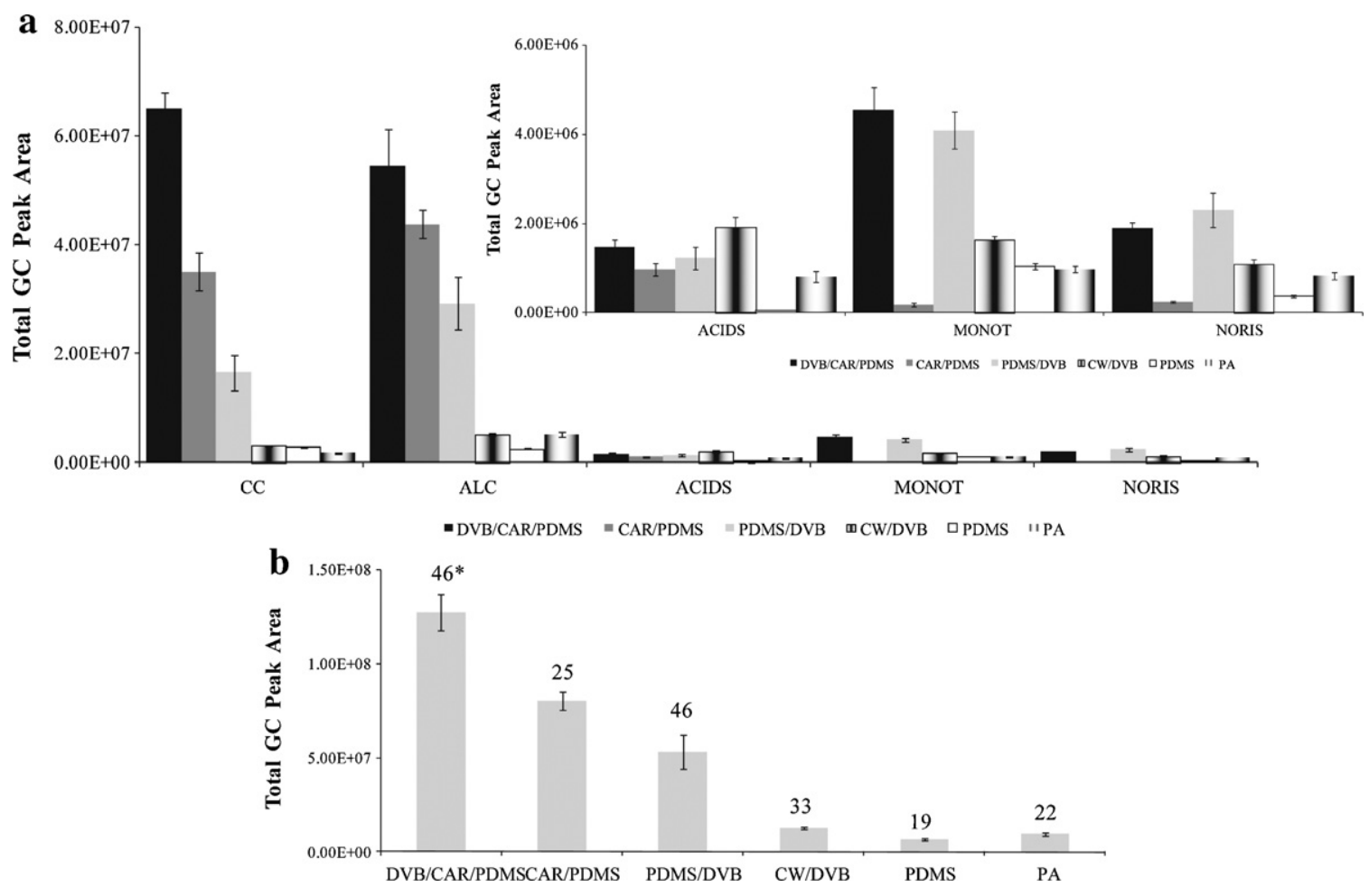

Fig. 1. Performance characteristics obtained for tested SPME fibres on chemical groups (a), and total GC peak area and $(*)$ number of identified compounds (b) of VOCs and SVOCs from the pulp of Bual grapes ( 30 min of extraction time at $40^{\circ} \mathrm{C}$ ): CC, carbonyl compounds; ALC, alcohols; MONOT, monoterpenoids; NORIS, $\mathrm{C}_{13}$ norisoprenoids.
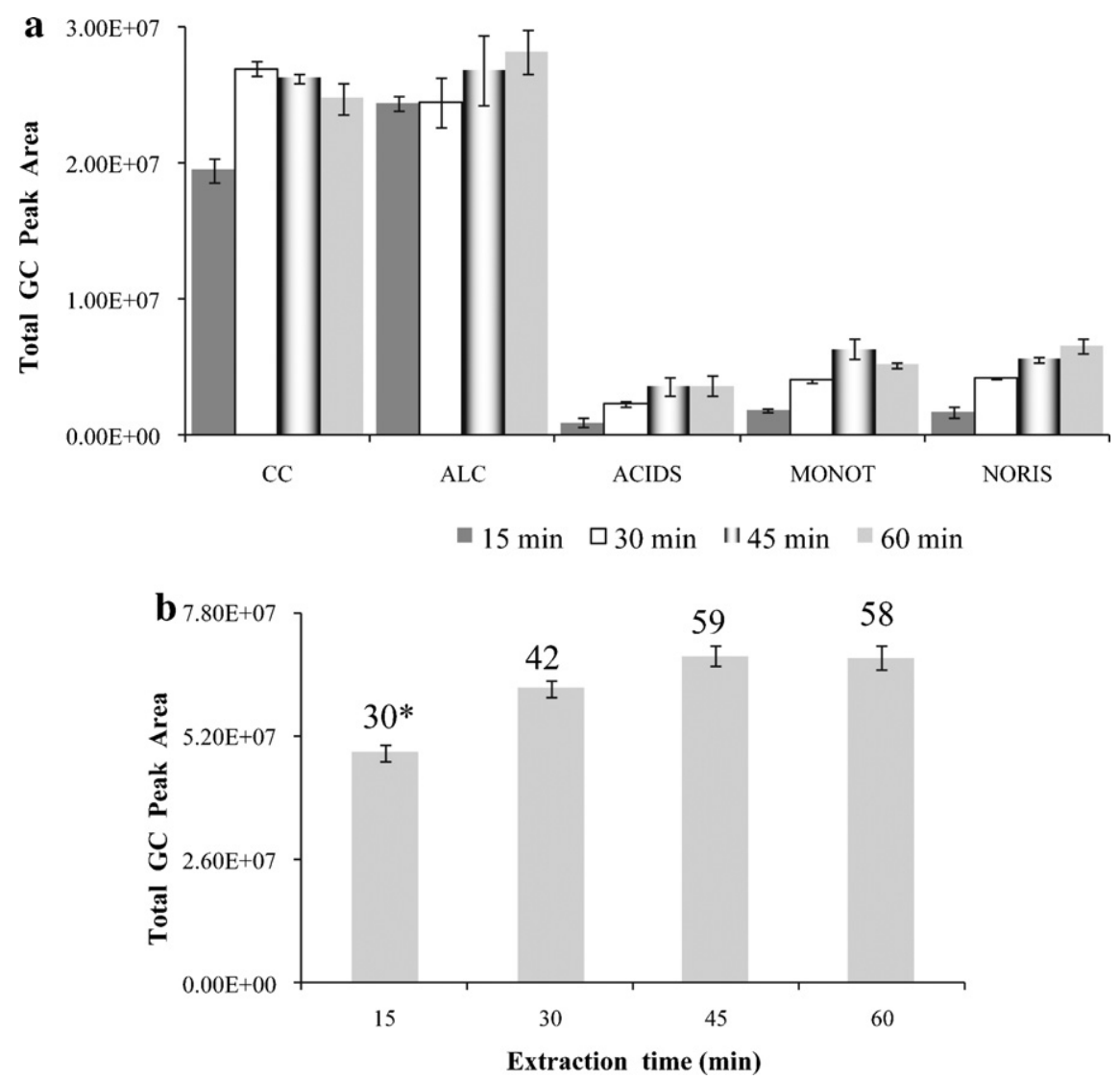

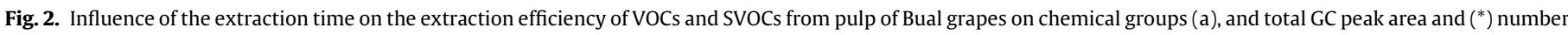

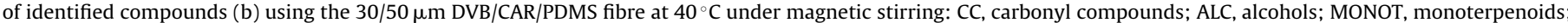
NORIS, $C_{13}$ norisoprenoids. 


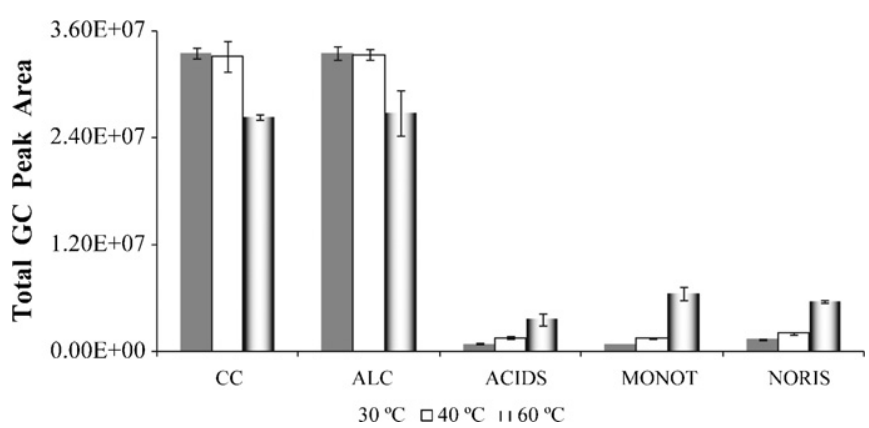

Fig. 3. Effect of temperature on HS-SPME $E_{D V B / C A R / P D M S}$ extraction efficiency of VOCs and SVOCs from pulp of Bual grapes (DVB/CAR/PDMS fibre during 45 min under constant stirring $(800 \mathrm{rpm})$ ): CC, carbonyl compounds; ALC, alcohols; MONOT, monoterpenoids; NORIS, $\mathrm{C}_{13}$ norisoprenoids. $\left(^{*}\right)$ Number of identified compounds.

extraction efficiency, different extraction temperatures (30, 40 and $60^{\circ} \mathrm{C}$ ) were tested. Higher temperatures were not used to prevent analytes degradation. The results concerning total GC peak area, number of identified compounds and RSD are illustrated in Fig. 3.

Reproducibility (RSD \%) was lower than $20 \%$ for all temperature tested. An increase in extraction temperature improved the extraction efficiency for acids, monoterpenoids and $\mathrm{C}_{13}$ norisoprenoids, while a decrease was observed for carbonyl compounds and alcoextraction efficiency for monoterpenoids was achieved for higher temperatures. A total of 55 VOCs and SVOCs have been identified at $60^{\circ} \mathrm{C}$, while using an extraction temperature of $40^{\circ} \mathrm{C}$ and $30^{\circ} \mathrm{C}$ were detected 45 and 39 compounds (Fig. 3b), respectively. An extraction temperature of $60^{\circ} \mathrm{C}$ was selected for all further optimisation steps, and pulp and skin analysis.

\subsubsection{Effect of ionic strength}

The addition of salt can influence the extraction efficiency in two ways: changing the properties of the boundary phase and decreasing the solubility of hydrophilic compounds in aqueous phase hols. Sánchez-Palomo et al. [20] also observed that the higher

(salting-out effect) [59]. Therefore, to check the ionic strength effect different amounts of sodium chloride (1,2 and $3 \mathrm{~g}$ ) were added to pulp of Bual. The ionic strength effect on the SPME extraction efficiency is shown in Fig. 4a.

An increasing on the extraction efficiency was observed from 1 to $2 \mathrm{~g}$ of $\mathrm{NaCl}$, reaching a maximum with $2 \mathrm{~g}$. Nevertheless, a decreasing was observed for $3 \mathrm{~g}$ of salt. This behaviour can be explained by considering two simultaneously occurring processes-initially analyte recovery increased due to the saltingout effect, whereby water molecules form hydration spheres around the ionic salt molecules. These hydration spheres reduce the content of water available to dissolve analyte molecules driving additional analytes into headspace and consequently fibre coating [60]. In competition with this process, at saturation state ( $3 \mathrm{~g})$, is the fact that molecules may participate in electrostatic interactions with the salt ions in solutions, thereby reducing their ability to move into the fibre coating [61]. Taking into account the results, $2 \mathrm{~g}$ of $\mathrm{NaCl}$ was selected for all further optimisation steps, and pulp and skin analysis.

\subsubsection{Influence of sample dilution}

In the case of complex matrices, such as grapes and wines, sample dilution may change the phase partitioning of VOCs and SVOCs between the sample and headspace, and eventually altering the volatile profile as competition for analytes between different phases is modified [7]. To examine such potential competitions and the possible limitations for quantitative headspace VOCs and SVOCs analysis, samples were diluted by adding $2.5,5.0$ and $10.0 \mathrm{~mL}$ of ultra-pure Milli-Q water to pulp of Bual grapes (using $2 \mathrm{~g}$ of sample). The data obtained was illustrated in Fig. $4 \mathrm{~b}$, showing that the response was enhanced with the addition of $2.5 \mathrm{~mL}$ of ultra-pure water, followed by a decreased when the volume of ultra-pure water is higher than $2.5 \mathrm{~mL}$. Addition of an aliquot of $5 \mathrm{~mL}$ of ultrapure Mill-Q water allowed higher reproducibility (RSD \%) than those obtained by using $2.5 \mathrm{~mL}$. Moreover, 53 VOCs were identified by using $5 \mathrm{~mL}$ of ultra-pure Milli-Q water, whereas using 2.5 and $10 \mathrm{~mL}$, only 50 and 46 compounds were identified, respectively. Addition of an aliquot of $5 \mathrm{~mL}$ of ultra-pure Milli-Q water
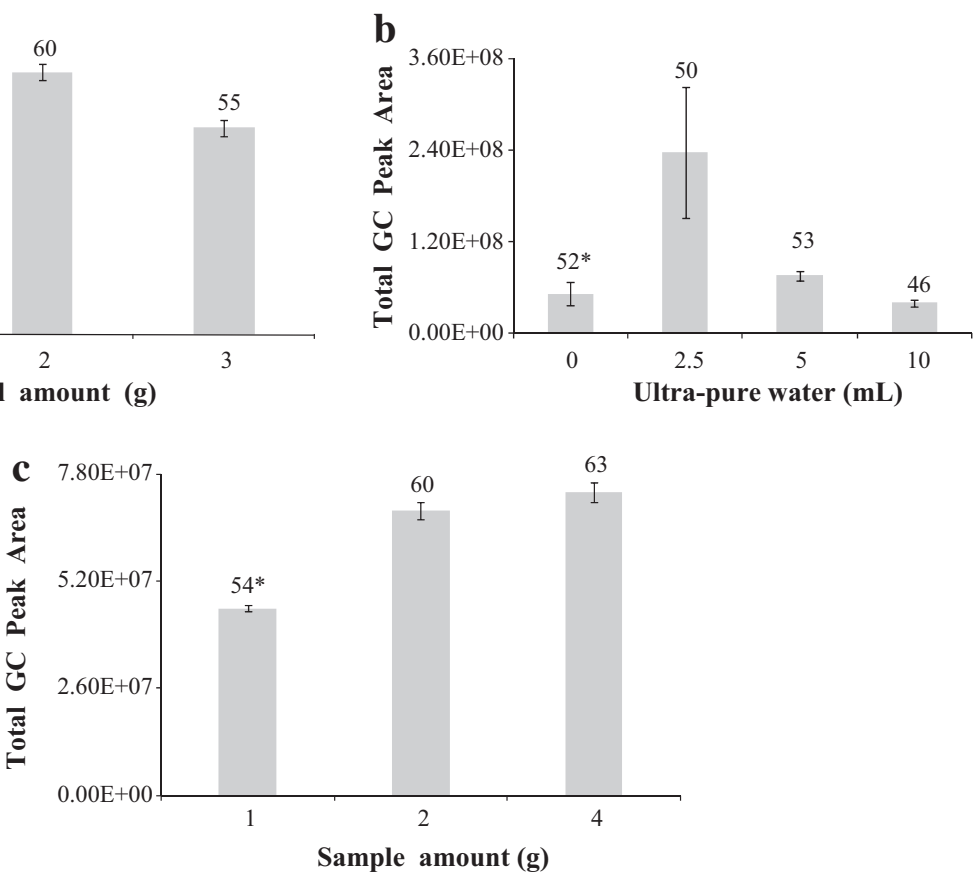

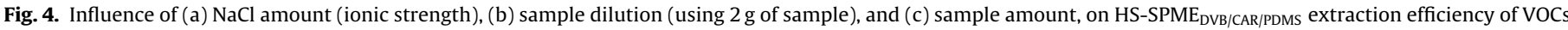
and SVOCs from pulp of Bual grapes ( $45 \mathrm{~min}$ of extraction time at $60^{\circ} \mathrm{C}$ under constant stirring $(800$ rpm $)$ ). $\left({ }^{*}\right)$ Number of identified compounds. 
Table 1

HS-SPME/GC-qMS optimised conditions for the determination of VOCs and SVOCs in pulp of Bual grapes.

\begin{tabular}{|c|c|}
\hline \multicolumn{2}{|l|}{ SPME } \\
\hline Grape sample volume & $4 \mathrm{~g}$ in $20 \mathrm{~mL}$ glass vial \\
\hline Salt addition & $2 \mathrm{~g} \mathrm{NaCl}$ \\
\hline SPME fibre & DVB/CAR/PDMS \\
\hline SPME mode & Headspace \\
\hline Sample extraction conditions & $60^{\circ} \mathrm{C}, 45 \mathrm{~min}$ \\
\hline Sample agitation speed (extraction) & $800 \mathrm{rpm}$ \\
\hline Fibre desorption conditions & $250^{\circ} \mathrm{C}, 7 \mathrm{~min}$ \\
\hline \multicolumn{2}{|l|}{ GC-qMS } \\
\hline GC column & $\begin{array}{l}\text { BP-20 }(30 \mathrm{~m} \times 0.25 \mathrm{~mm} \\
\text { I.D. } \times 0.25 \mu \mathrm{m} \text { film thickness })\end{array}$ \\
\hline Injection mode & Splitless \\
\hline GC oven program & $\begin{array}{l}40^{\circ} \mathrm{C}(5 \mathrm{~min}) \text { then ramped at } \\
2^{\circ} \mathrm{C} \mathrm{min}^{-1} \text { to } 220^{\circ} \mathrm{C}(20 \mathrm{~min})\end{array}$ \\
\hline Carrier gas & $\mathrm{He}$ \\
\hline Carrier gas flow-rate & $1.2 \mathrm{mLmin}^{-1}$ \\
\hline Transfer line temperature & $250^{\circ} \mathrm{C}$ \\
\hline GC run time & $115 \min$ \\
\hline Ionization type & Electronic impact (EI) \\
\hline Ionization energy & $70 \mathrm{eV}$ \\
\hline Ion source temperature & $230^{\circ} \mathrm{C}$ \\
\hline Detector voltage & $2100 \mathrm{~V}$ \\
\hline Mass fragments collected $(\mathrm{m} / \mathrm{z})$ & 30-300 a.m.u. \\
\hline Data acquisition & Full scan \\
\hline
\end{tabular}

was selected for all further optimisation steps, and pulp and skin analysis.

\subsubsection{Influence of sample amount}

Establishment of the sample volume/headspace volume ratio is a crucial parameter in the optimisation of a SPME procedure $[14,19]$. The amount of analyte extracted increases with the sample content up to a point, after which the sensitivity does not increase with further increasing in sample volume. Theoretically, optimum sample volume can be selected based on the estimated sample/headspace/coating distribution constant. In this study, to evaluate the influence of sample amount on the SPME extraction efficiency, three different assays using $1(1 / \beta=0.2), 2(1 / \beta=0.4)$ and $4 \mathrm{~g}(1 / \beta=0.5)$ of pulp from Bual grapes were performed, and the results are shown in Fig. 4c. The total GC peak areas increased slightly with sample amount. The highest extraction efficiency was achieved using $4 \mathrm{~g}$ of pulp, which correspond to a ratio of the volume of the liquid phase to the headspace volume $(1 / \beta)$ of 0.5 . Moreover, 63 VOCs and SVOCs were identified using $4 \mathrm{~g}$ of pulp from Bual grapes, while using 1 and $2 \mathrm{~g}$ of sample, were identified 60 and 54, respectively. The sample amount of $4 \mathrm{~g}$ was selected for all further optimisation steps, and pulp and skin analysis.

The selected HS-SPME/GC-qMS conditions are summarised in Table 1.

\subsection{Application of HS-SPME/GC-qMS methodology for analysis of VOCs and SVOCs in pulp and skins of Bual and Bastardo Vitis vinifera $L$. grapes}

Finally, in order to test the applicability of the optimised HSSPME/GC-qMS methodology, the global volatile signature of the pulp and skin from Vitis vinifera L. Bual and Bastardo grapes was established. More than 100 VOCs and SVOCs were identified in pulp and skin of both grapes varieties, belonging to different chemical groups (Table 2). A highly uneven distribution of VOCs and SVOCs between skin and pulp was observed. In both varieties, it was observed that the skin contained about volatiles ( 85 in Bual and 93 in Bastardo) than the corresponding pulp (68 and 71 in Bual and Bastardo grapes, respectively). A total of 27 monoterpenoids, 27 sesquiterpenoids, $10 \mathrm{C}_{13}$ norisoprenoids, 21 carbonyl compounds, 17 alcohols and 5 acids were identified.
Considering the GC peak areas, skins contained about $70 \%$ of the total volatiles present in grapes of both varieties. The GC peak area of sesquiterpenoids was 93 and 347 times higher in skin than in pulp of Bual and Bastardo grapes, respectively. This tendency was followed by, monoterpenoids (1.84 and 2.43), carbonyl compounds (1.55 and 1.96 times) and acids (4.27 and 3.85), respectively. Alcohols were found to be evenly distributed between skins and pulps of the two varieties, whereas $C_{13}$ norisoprenoids was associated primarily with the pulp (1.71 times higher) of the Bual grapes. In Bastardo grapes the $C_{13}$ norisoprenoids are uniformly distributed between the pulp and skin.

Because of the impact of monoterpenoids, sesquiterpenoids and $\mathrm{C}_{13}$ norisoprenoids on flavour and varietal character of Vitis vinifera L. varieties, particular attention was devoted to these chemical groups. Carbonyl compounds and alcohols, particularly the $\mathrm{C}_{6} \mathrm{com}-$ pounds, were also object of particular considerations as they can promote deleterious effect on wine aroma properties, due to their herbaceous notes.

The total GC peak area of monoterpenoids in pulp and skin of Bastardo grapes was found to be higher than that determined in pulp and skin of Bual grapes, besides the number of identified compounds being quite similar. Menthol, geraniol and linalool represented the major monoterpenoids identified in pulp of Bual grapes, while in skin menthol, geraniol, carvone and $p$-cymene were found the most dominant, accounting for 46 and $56 \%$ of the total monoterpenoids GC peak area, respectively. In pulp of Bastardo grapes, dihydrolinalool, geraniol, $\alpha$-terpineol, and dihydromyrcenol were the most abundant monoterpenoids, while in skin dehydrolinalool, geraniol and $\beta$-pinene were found to be the major ones, accounting for 59 and $61 \%$ of the total monoterpenoids GC peak area, respectively.

According to results obtained by PCA, the skin of Bastardo grapes (PC1 and PC2 positive) is mainly characterized by the presence of monoterpenoids (e.g. $\beta$-pinene, $\gamma$-terpinene, $(Z)-\beta$-ocimene, $(E)$ $\beta$-ocimene, $p$-cymene, and geranic acid). Moreover, this chemical group when present at concentration above their odour threshold (OT), could contribute with citrus-like, sweet and flowery notes [17]. The importance of monoterpenoids as grape and wine components is well known, due to their aroma properties, and as their profile can be used for characterisation of grape varieties.

A total of $10 \mathrm{C}_{13}$ norisoprenoids were detected in pulp and skin of both grape varieties, 7 from which were common to Bual and Bastardo grapes. The $\mathrm{C}_{13}$ norisoprenoid GC peak area was found to be considerable higher in pulp of Bual than in pulp of Bastardo and skin of both grapes (Table 2). This chemical group accounted for 7 and $5 \%$ of the total volatile profiles in pulp, and 2 and $2 \%$ of the total volatile profile in skin of Bual and Bastardo grapes, respectively. 1,1,6-Trimethyl-1,2-dihydro-naphthalene (TDN) was only identified in pulp of Bual, while $\alpha$-ionone was only identified in pulp of Bastardo grapes. (E)- $\beta$-Damascenone was the most abundant $C_{13}$ norisoprenoid identified in pulp of both grape varieties, whereas in skin $(E)-\beta$-damascenone, naphthalene and $\beta$-ionone were dominant. As can be observed in Fig. 5, the pulp of Bual (PC1 and PC2 negative) is mainly characterized by the presence of $C_{13}$ norisoprenoids, highlighting vitispirane I, vitispirane II, TDN, $(E)-\beta$ damascenone, and methyl dihydrojasmonate. This chemical group (derived from carotenoids degradation [62]), when present at concentration above their OT, can contribute for grape and wine aroma with characteristics camphor, honey-like or cassis notes. These compounds are also considered to be a quality factor and typical for each variety [62].

With regard to sesquiterpenoids their levels were found to be considerable higher in skin of Bual than in skin of Bastardo, and pulp of both varieties. Furthermore, the GC peak area of these volatiles in pulp and skin of Bual was 17 and 4 times higher than in pulp and skin of Bastardo grapes, respectively. Among them, 
Table 2

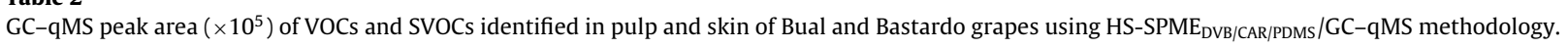

\begin{tabular}{|c|c|c|c|c|c|c|c|c|c|c|c|c|c|}
\hline \multirow[t]{3}{*}{ Peak $n^{\circ}$} & \multirow[t]{3}{*}{$\mathrm{RT}(\min )^{\mathrm{a}}$} & \multirow[t]{3}{*}{ R.I. calc ${ }^{\mathrm{b}}$} & \multirow[t]{3}{*}{ R.I. lit ${ }^{c}$} & \multirow[t]{3}{*}{$\operatorname{IEC}(m / z)^{\mathrm{d}}$} & \multirow[t]{3}{*}{ Chemical groups } & \multicolumn{8}{|c|}{ GC peak area $\left(10^{5}\right)^{\mathrm{e}}$ and $\mathrm{RSD} \%{ }^{\mathrm{f}}$} \\
\hline & & & & & & \multicolumn{4}{|l|}{$\overline{\text { Bual }}$} & \multicolumn{4}{|c|}{ Bastardo } \\
\hline & & & & & & $\overline{\text { Pulp }}$ & & Skin & & Pulp & & Skin & \\
\hline \multicolumn{14}{|c|}{ Monoterpenoids } \\
\hline 3 & 9.70 & 1132 & 1138 & 93 & $\beta$-Pinene & - & - & - & - & 1.23 & (18) & 45.47 & (20) \\
\hline 4 & 10.77 & 1161 & 1185 & 68 & Limonene ${ }^{g}$ & - & - & - & - & 3.91 & (17) & - & - \\
\hline 6 & 12.81 & 1208 & 1238 & 93 & $\gamma$-Terpinene & - & - & - & - & - & - & 4.23 & (13) \\
\hline 8 & 13.71 & 1225 & 1234 & 93 & (Z)- $\beta$-Ocimene & - & - & - & - & - & - & 2.11 & (13) \\
\hline 9 & 14.67 & 1242 & 1261 & 119 & p-Cymene ${ }^{g}$ & 0.50 & (1) & 5.07 & (3) & 1.49 & (10) & 8.29 & (16) \\
\hline 10 & 15.00 & 1248 & 1252 & 93 & (E)- $\beta$-Ocimene & - & - & - & - & - & - & 1.71 & (12) \\
\hline 25 & 25.83 & 1417 & 1431 & 117 & p-Cymenene & 0.59 & (1) & 0.53 & $(1)$ & 0.62 & (6) & 2.68 & (18) \\
\hline 26 & 26.66 & 1431 & 1439 & 59 & (Z)-Linalool oxide & 0.55 & (17) & 0.67 & (17) & 1.06 & (3) & 1.00 & (7) \\
\hline 33 & 29.27 & 1475 & 1443 & 59 & Dihydromyrcenol & 0.58 & (3) & - & - & 4.22 & (10) & 3.16 & (2) \\
\hline 36 & 30.16 & 1486 & 1498 & 95 & Camphor & 1.63 & (19) & - & - & - & - & - & - \\
\hline 43 & 34.04 & 1550 & 1557 & 71 & Linalool $^{g}$ & 3.99 & - & 2.94 & (18) & 3.06 & - & 5.11 & (3) \\
\hline 44 & 34.40 & 1555 & 1580 & 95 & Bornyl acetate & - & (14) & 1.47 & (3) & - & (2) & - & - \\
\hline 50 & 36.16 & 1583 & 1537 & 71 & Dihydrolinalool & 2.52 & (35) & 2.02 & (13) & 22.06 & (19) & 10.93 & (2) \\
\hline 52 & 36.45 & 1587 & 1579 & 71 & 4-Carvomenthenol & - & - & - & - & 0.45 & (17) & 1.73 & (9) \\
\hline 53 & 36.80 & 1592 & 1561 & 94 & $p$-Mentha-8-en-1-ol & 0.33 & (1) & 0.90 & (1) & 0.41 & (11) & 0.87 & (16) \\
\hline 59 & 38.89 & 1628 & 1639 & 71 & Mentholg & 5.42 & (8) & 5.19 & (1) & - & - & - & - \\
\hline 67 & 41.78 & 1676 & 1650 & 93 & (E)-Ocimenol & - & - & - & - & 0.24 & (1) & - & - \\
\hline 69 & 42.32 & 1684 & 1669 & 59 & $\alpha$-Terpineolg & 1.35 & (12) & 1.14 & $(4)$ & 4.68 & (3) & 7.34 & (7) \\
\hline 72 & 43.66 & 1707 & 1715 & 82 & Carvone & 3.35 & (13) & 7.23 & (10) & 0.45 & (8) & 1.12 & (13) \\
\hline 75 & 44.24 & 1718 & 1724 & 69 & Neral & 1.02 & (17) & 3.19 & (6) & 0.67 & (12) & 0.96 & (10) \\
\hline 83 & 46.70 & 1764 & 1771 & 69 & Citronellolg $^{g}$ & - & - & 2.42 & (6) & - & - & 2.08 & (6) \\
\hline 84 & 47.73 & 1782 & 1794 & 69 & Cumin aldehyde & - & - & 2.96 & (5) & - & - & 2.16 & (12) \\
\hline 86 & 48.49 & 1795 & 1798 & 69 & $\mathrm{Nerol}^{\mathrm{g}}$ & - & - & 1.67 & (12) & 0.70 & (9) & 4.38 & (3) \\
\hline 89 & 49.39 & 1812 & - & 148 & Estragole & - & - & 1.02 & (3) & - & - & 0.32 & (2) \\
\hline 92 & 51.79 & 1858 & 1862 & 43 & Geraniolg $^{g}$ & 6.09 & (4) & 14.22 & (20) & 9.14 & (5) & 27.30 & (9) \\
\hline 100 & 60.59 & 2003 & 2037 & 189 & Lilyal & 3.07 & (20) & 4.49 & (16) & 2.08 & (16) & 1.23 & (18) \\
\hline \multirow[t]{3}{*}{106} & 74.75 & 2035 & 1995 & 69 & Geranic acidg & - & - & - & - & - & - & 3.10 & (16) \\
\hline & & & & & Subtotal (GC Peak area) & 30.99 & (3) & 57.13 & (9) & 56.47 & (9) & 137.28 & (8) \\
\hline & & & & & Subtotal compounds number & 14 & & 17 & & 17 & & 22 & \\
\hline \multicolumn{14}{|c|}{ Sesquiterpenoids } \\
\hline 28 & 27.48 & 1445 & 1471 & 105 & $\alpha$-Ylangene & 2.29 & (34) & 252.87 & (10) & - & - & 22.08 & (14) \\
\hline 31 & 28.39 & 1459 & 1463 & 161 & $\alpha$-Cubebene & - & - & 21.04 & (13) & - & - & 4.83 & (11) \\
\hline 34 & 29.77 & 1481 & 1512 & 81 & $(-)-\beta$-Bourbonene & - & - & 428.75 & (10) & - & - & 46.30 & (11) \\
\hline 42 & 33.59 & 1542 & 1519 & 161 & $\beta$-Cubebene & - & - & 25.34 & (6) & - & - & 8.01 & (15) \\
\hline 46 & 35.02 & 1565 & 1575 & 93 & $\beta$-Caryophyllene & - & - & 5.89 & (11) & - & - & 6.85 & (7) \\
\hline 48 & 35.65 & 1575 & - & 161 & (+)-Epi-bicyclosesquiphellandrene & - & - & 50.32 & (4) & - & - & 15.75 & (14) \\
\hline 51 & 36.43 & 1587 & 1559 & 161 & (-)-Isoledene & 0.45 & (1) & 10.83 & (11) & - & - & 5.57 & (19) \\
\hline 55 & 37.40 & 1602 & 1600 & 161 & (+)-Aromadendrene ${ }^{g}$ & - & - & 14.38 & (12) & - & - & 5.32 & (11) \\
\hline 56 & 37.51 & 1604 & 1596 & 161 & $\beta$-Gurjunene & - & - & 3.09 & (3) & - & - & 2.62 & (19) \\
\hline 58 & 38.30 & 1617 & 1625 & 121 & $\gamma$-Elemene & - & - & 3.87 & (12) & - & - & 7.18 & $(22)$ \\
\hline 61 & 39.45 & 1637 & 1663 & 93 & $\alpha$-Caryophyllene & - & - & 3.14 & (5) & - & - & 78.01 & (17) \\
\hline 62 & 39.49 & 1638 & 1616 & 161 & Alloaromadendrene & - & - & 8.94 & (19) & - & - & 4.83 & (11) \\
\hline 63 & 39.72 & 1642 & 1643 & 161 & $\alpha$-Humulene ${ }^{g}$ & - & - & 9.27 & (9) & - & - & 0.51 & (3) \\
\hline 65 & 40.87 & 1661 & 1681 & 161 & $\gamma$-Muurolene & 0.85 & (1) & 20.26 & (5) & - & - & 11.67 & (12) \\
\hline 66 & 41.25 & 1667 & 1682 & 161 & $\gamma$-Selinene & - & - & 9.73 & (17) & - & - & 3.30 & (13) \\
\hline 68 & 41.84 & 1677 & 1691 & 161 & $\alpha$-Amorphene & - & - & 17.33 & (21) & - & - & 22.18 & (8) \\
\hline 70 & 42.39 & 1686 & 1688 & 161 & Epizonarene & - & - & 59.29 & (15) & - & - & 3.84 & (7) \\
\hline 71 & 42.59 & 1689 & 1705 & 161 & Germacrene D & - & - & 12.64 & (7) & - & - & 4.37 & (10) \\
\hline 76 & 44.62 & 1725 & 1727 & 161 & $\alpha$-Muurolene & - & - & 5.14 & (1) & - & - & 15.04 & (9) \\
\hline 77 & 44.82 & 1729 & 1730 & 161 & $\alpha$-Bisabolene & 5.00 & (13) & 271.13 & (9) & - & - & 16.62 & (15) \\
\hline
\end{tabular}


Table 2 (Continued)

\begin{tabular}{|c|c|c|c|c|c|c|c|c|c|c|c|c|c|}
\hline \multirow[t]{3}{*}{ Peak n } & \multirow[t]{3}{*}{$\mathrm{RT}(\min )^{\mathrm{a}}$} & \multirow[t]{3}{*}{ R.I. calc ${ }^{b}$} & \multirow[t]{3}{*}{ R.I. lit ${ }^{c}$} & \multirow[t]{3}{*}{$\operatorname{IEC}(m / z)^{\mathrm{d}}$} & \multirow[t]{3}{*}{ Chemical groups } & \multicolumn{8}{|c|}{ GC peak area $\left(10^{5}\right)^{\mathrm{e}}$ and RSD \% ${ }^{\mathrm{f}}$} \\
\hline & & & & & & \multicolumn{4}{|l|}{$\overline{\text { Bual }}$} & \multicolumn{4}{|c|}{ Bastardo } \\
\hline & & & & & & Pulp & & Skin & & Pulp & & Skin & \\
\hline 79 & 45.73 & 1746 & 1738 & 161 & Bicyclogermacrene & - & - & 1.47 & (3) & - & - & 1.41 & (9) \\
\hline 82 & 46.58 & 1761 & 1752 & 105 & $\delta$-Cadinene & - & - & 27.29 & (14) & - & - & 5.01 & (11) \\
\hline 88 & 49.06 & 1806 & 1827 & 159 & Calamenene & 2.88 & (18) & 71.53 & (16) & - & - & 12.43 & (20) \\
\hline 95 & 53.52 & 1890 & 1906 & 157 & $\alpha$-Calacorene & - & - & 37.26 & (14) & - & - & 5.93 & (10) \\
\hline 103 & 68.75 & 2022 & - & 183 & Cadalene & 2.57 & (6) & 1.04 & (9) & 0.20 & (6) & 0.54 & (16) \\
\hline 105 & 72.37 & 2030 & 2009 & 69 & (Z)-Nerolidolg ${ }^{\mathrm{g}}$ & 0.75 & (14) & - & - & 0.69 & (15) & - & - \\
\hline \multirow[t]{3}{*}{107} & 76.67 & 2039 & - & 183 & Guaiazulene $^{g}$ & - & - & 2.96 & $(4)$ & - & - & 0.34 & $(10)$ \\
\hline & & & & & Subtotal (GC peak area) & 14.79 & (13) & 1374.80 & (9) & 0.89 & (13) & 310.54 & (7) \\
\hline & & & & & Subtotal compounds number & 7 & & 26 & & 2 & & 26 & \\
\hline \multirow{2}{*}{\multicolumn{14}{|c|}{$\begin{array}{cc}\mathrm{C}_{13} & \text { Norisoprenoids } \\
39 & 30.91\end{array}$}} \\
\hline & & & & & & & & & & & & & \\
\hline 40 & 30.93 & 1498 & 1529 & 192 & Vitispirane II & 4.15 & (1) & 0.36 & (2) & 0.34 & (8) & 0.53 & (14) \\
\hline 54 & 36.97 & 1595 & 1598 & 137 & $\beta$-Ciclocitral & 0.73 & (7) & 0.70 & $(1)$ & 1.61 & (7) & 3.77 & (15) \\
\hline 73 & 43.76 & 1709 & 1714 & 128 & Naphthalene & 7.83 & (18) & 14.15 & (17) & 1.39 & (5) & 9.17 & (14) \\
\hline 74 & 43.80 & 1711 & 1719 & 157 & TDN & 0.96 & (1) & - & - & - & - & - & - \\
\hline 87 & 48.78 & 1800 & 1801 & 69 & $(E)-\beta$-Damascenone ${ }^{g}$ & 57.94 & (4) & 15.42 & $(32)$ & 22.17 & (18) & 9.22 & $(4)$ \\
\hline 90 & 50.36 & 1831 & 1809 & 121 & $\alpha$-Ionone $^{g}$ & - & - & - & - & 0.42 & (17) & - & - \\
\hline 94 & 53.48 & 1889 & 1904 & 95 & $\alpha$-Ionolg $^{\mathrm{g}}$ & 5.97 & (14) & - & - & 5.99 & (22) & - & - \\
\hline 97 & 55.03 & 1918 & 1912 & 177 & $\beta$-Ionone ${ }^{g}$ & 3.03 & (6) & 11.40 & $(8)$ & 7.94 & (2) & 14.80 & (17) \\
\hline \multirow[t]{3}{*}{104} & 72.09 & 2029 & - & 83 & Methyl dihydrojasmonate & 6.56 & (14) & 9.74 & $(15)$ & 3.28 & (15) & 2.94 & (13) \\
\hline & & & & & Subtotal (GC peak area) & 88.98 & (3) & 51.95 & $(15)$ & 43.35 & $(11)$ & 40.83 & $(10)$ \\
\hline & & & & & Subtotal compounds number & 9 & & 7 & & 9 & & 7 & \\
\hline \multicolumn{14}{|l|}{ Alcohols } \\
\hline 11 & 16.33 & 1269 & 1255 & 55 & 1-Pentanolg & 0.99 & $(20)$ & 0.67 & $(1)$ & 0.98 & (14) & - & - \\
\hline 14 & 20.04 & 1311 & 1273 & 45 & 2-Heptanol & - & - & - & - & 2.17 & (6) & 4.62 & (11) \\
\hline 16 & 22.05 & 1360 & 1360 & 56 & 1-Hexanolg & 130.05 & (18) & 57.21 & (13) & 78.17 & (12) & 67.70 & (10) \\
\hline 17 & 22.71 & 1370 & 1386 & 41 & (E)-3-Hexen-1-ol & 1.88 & (17) & 2.18 & (3) & 0.66 & (22) & 0.64 & (10) \\
\hline 18 & 22.94 & 1373 & - & 87 & 3-Ethyl-3-heptanol & 0.51 & (1) & - & - & 2.88 & $(4)$ & - & - \\
\hline 20 & 23.86 & 1386 & 1391 & 41 & (Z)-3-Hexen-1-ol & 1.13 & (6) & 1.89 & (7) & 12.86 & (13) & 11.48 & (5) \\
\hline 23 & 25.25 & 1407 & 1400 & 57 & (E)-2-Hexen-1-olg & 144.81 & (14) & 89.29 & (4) & 87.95 & (2) & 70.99 & (19) \\
\hline 27 & 26.68 & 1432 & 1439 & 55 & 1-Heptanol & 0.55 & (10) & 1.28 & (3) & 0.79 & (5) & 1.85 & (19) \\
\hline 29 & 28.02 & 1453 & 1445 & 57 & 1-Octen-3-olg & 15.12 & (17) & 8.52 & (7) & 15.04 & (11) & 11.03 & (10) \\
\hline 38 & 30.40 & 1485 & 1492 & 57 & 2-Ethylhexan-1-olg & 14.94 & (27) & 5.50 & (2) & 15.30 & (6) & 4.87 & (11) \\
\hline 45 & 34.51 & 1557 & 1553 & 55 & 1-Octanol ${ }^{\mathrm{g}}$ & 2.06 & (10) & 4.04 & (15) & 1.33 & (7) & 2.17 & (17) \\
\hline 57 & 38.01 & 1612 & 1610 & 57 & (Z)-2-Octen-1-ol & 1.08 & (23) & 2.18 & (3) & 1.87 & (11) & 1.75 & (4) \\
\hline 64 & 40.61 & 1657 & 1654 & 56 & 1-Nonanol & 1.12 & (19) & 5.29 & (3) & 1.57 & (4) & 3.19 & (14) \\
\hline 81 & 46.53 & 1760 & 1765 & 55 & 1-Decanol ${ }^{g}$ & 0.64 & (16) & - & - & 0.44 & (18) & - & - \\
\hline 93 & 52.34 & 1868 & 1865 & 79 & Benzyl alcoholg & 4.49 & (2) & 140.73 & (15) & 9.24 & (10) & 47.82 & (6) \\
\hline 96 & 54.09 & 1899 & 1905 & 91 & 2-Phenylethyl alcoholg & 1.05 & (4) & 25.50 & (12) & 8.88 & (11) & 64.46 & (10) \\
\hline \multirow[t]{3}{*}{99} & 57.53 & 1965 & 1955 & 55 & 1-Dodecanol ${ }^{\mathrm{g}}$ & - & - & 0.46 & $(1)$ & 0.80 & (18) & 1.03 & $(25)$ \\
\hline & & & & & Subtotal (GC peak area) & 320.42 & $(13)$ & 344.74 & $(10)$ & 240.93 & $(4)$ & 293.60 & (6) \\
\hline & & & & & Subtotal compounds number & 15 & & 14 & & 17 & & 14 & \\
\hline
\end{tabular}




\begin{tabular}{|c|c|c|c|c|c|c|c|c|c|c|c|c|c|}
\hline \multicolumn{14}{|c|}{ Carbonyl compounds } \\
\hline 1 & 7.00 & 1043 & 1064 & 44 & Hexanal $^{g}$ & 270.35 & $(10)$ & 231.41 & (14) & 162.60 & (19) & 172.10 & (7) \\
\hline 2 & 9.20 & 1118 & 1132 & 41 & (Z)-3-Hexenal & 10.92 & $(23)$ & 37.10 & (17) & 3.51 & (21) & 2.83 & (20) \\
\hline 5 & 11.07 & 1169 & 1174 & 44 & Heptanal & 2.36 & (17) & - & - & 1.70 & (20) & 1.73 & (1) \\
\hline 7 & 13.20 & 1216 & 1221 & 41 & (E)-2-Hexenalg & 365.92 & (10) & 757.63 & (5) & 140.28 & (9) & 430.27 & (5) \\
\hline 12 & 16.77 & 1276 & 1280 & 41 & Octanal & 3.51 & (15) & 3.16 & (5) & 3.67 & (7) & 2.89 & (11) \\
\hline 13 & 19.23 & 1314 & 1299 & 41 & (E)-2-Heptenal & 17.26 & (12) & 10.04 & (10) & 27.23 & (13) & 11.88 & (14) \\
\hline 15 & 20.29 & 1332 & 1319 & 43 & 6-Methyl-5-hepten-2-one & 5.83 & (12) & 6.22 & (15) & 10.33 & (21) & 6.57 & (15) \\
\hline 19 & 23.42 & 1380 & 1389 & 57 & Nonanal & 8.10 & (25) & 31.77 & (17) & 7.72 & (12) & 19.99 & (13) \\
\hline 21 & 24.69 & 1383 & 1391 & 81 & $(E, E)$-2,4-Hexadienal & 9.41 & (6) & - & - & 5.29 & (7) & 10.64 & (12) \\
\hline 22 & 25.03 & 1403 & - & 109 & 6-Methyl-3,5-heptadiene-2-one & - & - & - & - & 0.57 & (8) & 2.25 & (7) \\
\hline 24 & 25.71 & 1415 & 1412 & 41 & (E)-2-Octenal & 8.78 & (23) & 5.84 & (10) & 10.97 & (14) & 15.72 & (15) \\
\hline 32 & 28.43 & 1460 & 1455 & 81 & $(E, E)-2,4$-Heptadienal & 3.61 & (12) & 6.49 & (1) & 10.54 & (13) & 41.40 & (7) \\
\hline 35 & 30.07 & 1485 & 1483 & 81 & $(Z, Z)-2,4$-Heptadienal & 2.83 & (21) & 11.73 & (7) & 13.36 & (15) & 63.05 & (15) \\
\hline 37 & 30.24 & 1488 & 1496 & 43 & Decanal & 6.26 & (4) & 4.01 & (19) & 1.85 & $(4)$ & 4.29 & (14) \\
\hline 41 & 32.39 & 1523 & 1527 & 43 & (E)-2-Nonenalg & 0.74 & (18) & 3.54 & (11) & 2.32 & (14) & 6.73 & $(20)$ \\
\hline 47 & 35.45 & 1572 & 1555 & 81 & $(E, E)-2,4$-Octadienal & 0.68 & (1) & 4.87 & (9) & 1.71 & (13) & 6.51 & (1) \\
\hline 49 & 35.86 & 1578 & 1569 & 81 & $(E, E)-2,6$-Nonadienal & 0.48 & (13) & 0.65 & (2) & 1.34 & (14) & 3.35 & (21) \\
\hline 60 & 38.96 & 1619 & 1635 & 43 & (E)-2-Decenal & 3.93 & (19) & 5.70 & (17) & 2.33 & (10) & 2.91 & (1) \\
\hline 78 & 45.20 & 1736 & 1745 & 70 & (E)-2-Undecanal & 1.53 & (23) & - & - & 2.59 & (15) & - & - \\
\hline 80 & 46.09 & 1752 & 1770 & 81 & $(E, E)-2,4$-Decadienal ${ }^{g}$ & - & - & - & - & 1.30 & (9) & - & - \\
\hline \multirow[t]{3}{*}{85} & 48.47 & 1795 & 1782 & 81 & (Z,Z)-2,4-Decadienal & 0.67 & $(27)$ & 1.20 & $(8)$ & 1.16 & (10) & 2.06 & $(13)$ \\
\hline & & & & & Subtotal (GC peak area) & 723.17 & $(8)$ & 1121.36 & (6) & 412.37 & (7) & 807.17 & (3) \\
\hline & & & & & Subtotal compounds number & 19 & & 16 & & 21 & & 19 & \\
\hline \multicolumn{14}{|c|}{ Acids } \\
\hline 30 & 28.14 & 1455 & 1457 & 43 & Acetic acidg & - & - & 5.71 & (1) & 9.47 & (17) & 58.88 & (13) \\
\hline 91 & 50.80 & 1839 & 1847 & 60 & Hexanoic acidg & 27.88 & (9) & 90.43 & (6) & 24.62 & (15) & 68.18 & (4) \\
\hline 98 & 57.07 & 1957 & 1962 & 73 & 2-Hexenoic acid & 1.39 & (10) & 29.34 & (7) & 5.29 & $(4)$ & 28.23 & (12) \\
\hline 101 & 61.83 & 2007 & 2038 & 60 & Octanoic acid ${ }^{g}$ & 0.48 & (6) & 1.33 & (12) & 0.93 & (14) & 1.54 & (14) \\
\hline \multirow[t]{5}{*}{102} & 66.93 & 2018 & 2026 & 60 & Nonanoic acid & 0.59 & (8) & 2.64 & $(21)$ & 0.81 & $(17)$ & 1.33 & $(7)$ \\
\hline & & & & & Subtotal (GC peak area) & 30.34 & $(8)$ & 129.45 & (4) & 41.12 & (12) & 158.16 & (5) \\
\hline & & & & & Subtotal compounds number & 4 & & 5 & & 5 & & 5 & \\
\hline & & & & & Total (GC peak area) & 1208.69 & (7) & 3079.43 & (8) & 795.13 & $(4)$ & 1747.58 & (3) \\
\hline & & & & & Total compounds number & 68 & & 85 & & 71 & & 93 & \\
\hline
\end{tabular}

a Retention times.

b Retention index calculated to BP-20 columns.

c Retention index reported in the literature for BP-20 columns or equivalents [27-55].

d Ion extraction chromatogram, $m / z$ used to obtained the GC peak area of each compound.

e Mean of three replicates.

${ }^{\mathrm{f}}$ Relative standard deviation.

${ }^{\mathrm{g}}$ Identification confirmed by comparing mass spectra and retention time with those of authentic standard. 


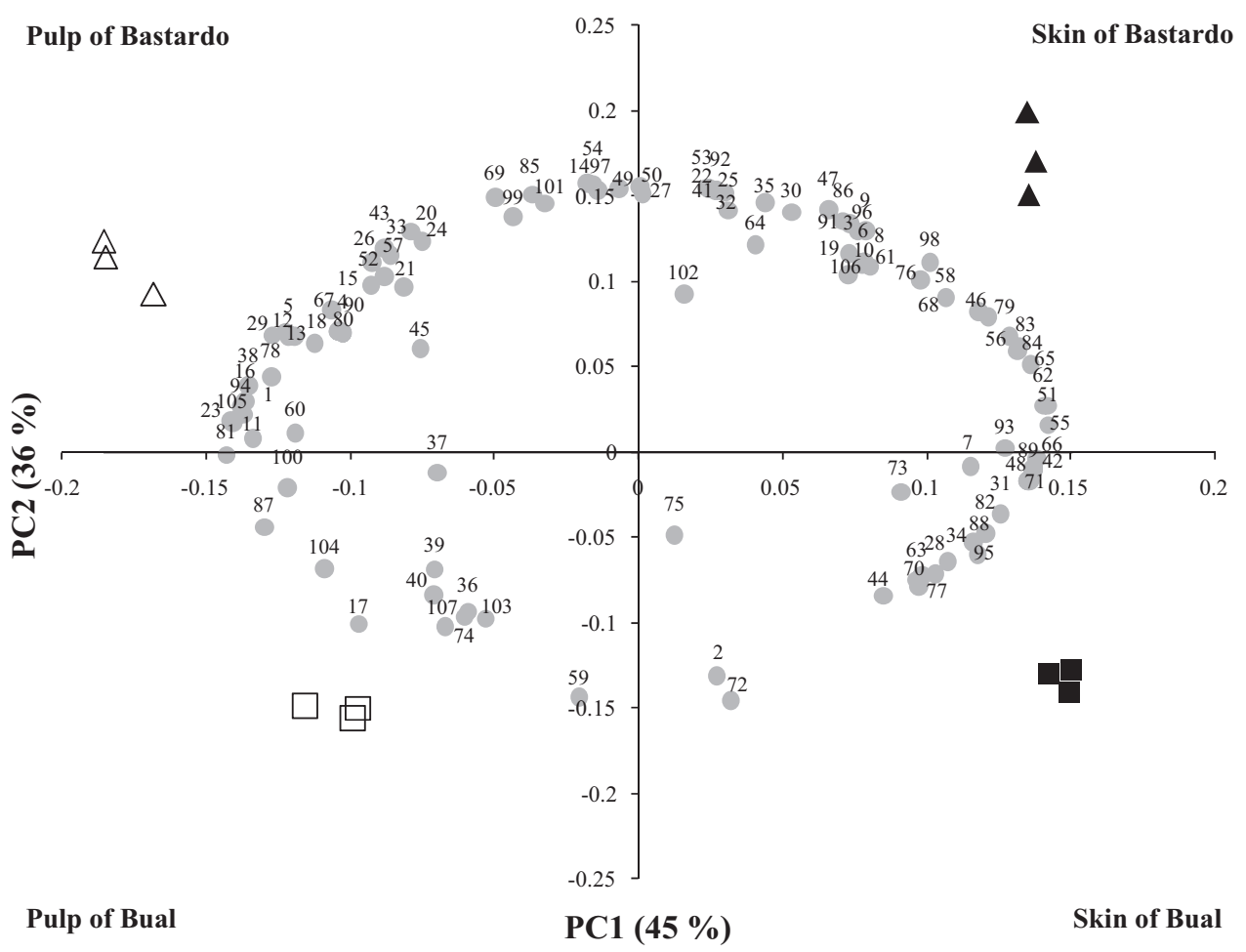

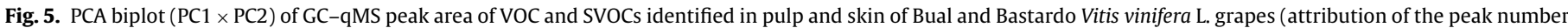
shown in Table 2).

$\beta$-bourbonene, $\alpha$-ylangene, $\alpha$-bisabolene, calamenene and $\alpha$ caryophylene, are predominant in both varieties. A highly uneven distribution was observed, 27 sesquiterpenoids identified in studied grapes. $\alpha$-Ylangene, $(-)$-isoledene, $\gamma$-muurolene, $\alpha$-bisabolene, and calamanene were only identified in pulp of Bual, whereas cadalene and $(Z)$-nerolidol were common to both pulp grapes. This chemical group, when present at concentration higher than their OT, can contribute for grape and wine aroma with woody, spice, sweet, floral, clove, musty oil and fresh notes [63]. Sesquiterpenoids have been related with different health applications, mainly antiinflammatory, anti-HIV, antibacterial and antitumoral activity [17].

Carbonyl compounds were quantitatively the largest group of the VOCs and SVOCs in Bual and Bastardo grapes. The group is composed mainly by $\mathrm{C}_{6}$ aldehydes (e.g. (E)-2-hexenal and hexanal), which found to be the major constituent of the skin and pulp of both investigated varieties. These compounds, products of the enzymatic breakdown of unsaturated fatty acids, when present at concentration above its OT, can contribute with herbaceous notes, while nonanal and decanal could exhibit soapy, citrus-like and green notes $[3,64]$, respectively.

The major alcohols identified, in skin and pulp of both varieties, were 1-hexanol and (E)-2-hexen-1-ol and, followed by benzyl and phenylethyl alcohols. In Bual grapes $C_{6}$ alcohols were found mainly in pulp, while in Bastardo grapes they found to be uniformly distributed among pulp and skins. Alcohols, whose origin was reported as being related mainly to the lipooxygenase activity of the grape and/or juice aeration, are reported to contribute more to the intensity of the odour of the wine than to its quality [65]. The GC peak area of the aromatic alcohols was found to be 3 times higher in pulp of Bastardo than pulp of Bual grapes. Benzyl alcohol and phenylethyl alcohol are associated with sweet and flowery notes and its contribution can be considered as a positive characteristic, especially for varieties with a poor varietal character. The pulp of Bastardo placed in PC1 negative and PC2 positive is mainly characterized by the presence of $C_{6}$ alcohols and $C_{6}$ aldehydes, highlighting hexanal, hexan-1-ol, (E)-2-hexen-1-ol, 2-ethylhexan-1-ol.

\section{Concluding remarks}

HS-SPME $E_{\mathrm{DVB} / \mathrm{CAR} / \mathrm{PDMS}}$ combined with GC-qMS provides a suitable and solvent-free approach for the establishment of global volatile signature of pulp and skin of grapes from different varieties.

Since SPME extraction technique is very sensitive to experimental conditions, several extraction-influencing parameters were optimised. Consequently, DVB/CAR/PDMS fibre was found to afford the most efficient extraction of the analytes released to the headspace. An extraction temperature of $60^{\circ} \mathrm{C}$ was found to be optimum to ensure efficient transfer from the headspace to the fibre while an extraction time of 45 min was considered sufficient.

More than 100 VOCs and SVOCs distributed over six chemical groups (mono and sesquiterpenoids, $\mathrm{C}_{13}$ norisoprenoids, alcohols, carbonyl compounds, and acids) were detected in the pulp and skin of Bual and Bastardo Vitis vinifera L. varieties. The data obtained showed that mono and sesquiterpenoids, carbonyl compounds and acids are mainly present in skin than in pulp of both grapes varieties under study. The high number of monoterpenoid and sesquiterpenoids identified in skin of both grapes suggests that these varieties are potential sources of these chemical groups. The most abundant ones were the $\beta$-bourbonene, $\alpha$-bisabolene and $\alpha$-ylangene in skin of Bual grapes, whereas $\alpha$-caryophyllene and $\beta$-bourbonene were predominant in the skin of Bastardo grapes.

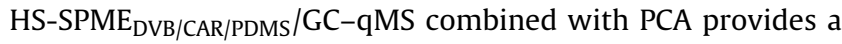
powerful tool to establish the global volatile signature of both grape varieties. Skins from both varieties were characterized mainly by the presence of mono (Bastardo) and sesquiterpenoids (Bual), which suggests that wine aroma properties could be increased if skin maceration (a procedure that promotes their transference to juice) is applied. Also, for the Bastardo variety, a special attention should be taken during winemaking procedure to avoid possible deleterious effects associated with the presence of $\mathrm{C}_{6}$ alcohols and $\mathrm{C}_{6}$ aldehydes that characterize its pulp composition. This knowledge represents a suitable tool to support in a objective way the winemaker decision based on the varieties potentialities. 


\section{Acknowledgements}

R. Perestrelo thanks the financial support of Fundação para a Ciência e Tecnologia (FCT) through PhD grant (SFRH/BD/38855/2007). The authors thank the financial support of MS Portuguese Networks (REDE/1508/RNEM/2005), Pluriannual base funding (QUI-Madeira-674) and Research Unit 62/94, QOPNA. The authors are grateful to Instituto do Vinho, do Bordado e do Artesanato da Madeira (IVBAM) for providing the grape samples used in this study.

\section{References}

[1] C. Yang, Y. Wang, Z. Liang, P. Fan, B. Wu, L. Yang, Y. Wang, S. Li, Food Chem. 114 (2009) 1106-1114.

[2] E.S. Palomo, M.S. Pérez-Coello, M.C. Díaz-Maroto, M.A.G. Viñas, M.D. Cabezudo, Food Chem. 95 (2006) 279-289.

[3] V. Canuti, M. Conversano, M.L. Calzi, H. Heymann, M.A. Matthews, S.E. Ebeler, J. Chromatogr. A 1216 (2009) 3012-3022.

[4] S.C. Diéguez, L.C. Lois, E.F. Gómez, M.L. Peña, LWT-Food Sci. Technol. 36 (2003) 585-590.

[5] L. Rosillo, M.R. Salinas, J. Garijo, G.L. Alonso, J. Chromatogr. A 847 (1999) 155-159.

[6] S.M. Bureau, A.J. Razungles, R.L. Baumes, J. Sci. Food Agric. 80 (2000) 2012-2020.

[7] A. Nasi, P. Ferranti, S. Amato, L. Chianese, Food Chem. 110 (2008) 762-768.

[8] C.L. Bayonove, R.E. Cordonnier, R. Ratier, C. R. Acad. Agric. Fr. 60 (1974) 1321-1329.

[9] R. Cordonnier, C. Bayonove, Connaiss. Vigne. Vin. 15 (1981) 269-286.

[10] O. Lamikanra, D. Garlick, Food Chem. 26 (1987) 245-251.

[11] J. Marais, A. Rapp, S. Afr. J. Enol. Viticult. 9 (1988) 22-30.

[12] M.E.O. Mamede, G.M. Pastore, Food Chem. 96 (2006) 586-590.

[13] E. Sánchez-Palomo, M.E. Alañón, M.C. Díaz-Maroto, M.A. González-Viñas, M.S. Pérez-Coello, Talanta 79 (2009) 871-876.

[14] I. Lukić, M. Banović, D. Peršurić, S. Radeka, B. Sladonja, J. Chromatogr. A 1101 (2006) 238-244.

[15] M. Vilanova, C. Sieiro, J. Food Compos. Anal. 19 (2006) 694-697.

[16] F. Guo, L. Huang, S. Zhou, T. Zhang, Y. Liang, Anal. Chim. Acta 570 (2006) 73-78

[17] E. Coelho, S.M. Rocha, I. Delgadillo, M.A. Coimbra, Anal. Chim. Acta 563 (2006) 204-214.

[18] E. Coelho, S.M. Rocha, A.S. Barros, I. Delgadillo, M.A. Coimbra, Anal. Chim. Acta 597 (2007) 257-264.

[19] C.M. Kalua, P.K. Boss, J. Chromatogr. A 1192 (2008) 25-35.

[20] E. Sánchez-Palomo, M.C. Díaz-Maroto, M.S. Pérez-Coello, Talanta 66 (2005) 1152-1157.

[21] S.M. Rocha, E. Coelho, J. Zrostlíková, I. Delgadillo, M.A. Coimbra, J. Chromatogr. A 1161 (2007) 292-299.

[22] C.M. Kalua, P.K. Boss, J. Agric. Food Chem. 57 (2009) 3818-3830.

[23] S.M. Rocha, P. Coutinho, A. Barros, I. Delgadillo, M.A. Coimbra, J. Chromatogr. A 1114 (2006) 188-197.

[24] R. Perestrelo, M. Caldeira, F. Rodrigues, J.S. Câmara, J. Sep. Sci. 31 (2008) 1841-1850.
[25] J. Vinholes, M.A. Coimbra, S.M. Rocha, J. Chromatogr. A 1216(2009) 8398-8403.

[26] H. Van Den Dool, P.D. Kratz, J. Chromatogr. A 11 (1963) 463-471.

[27] A. Hognadottir, R.L. Rouseff, J. Chromatogr. A 998 (2003) 201-211.

[28] A.J. Macleod, N.M. Pieris, Phytochemistry 21 (1982) 117-119.

[29] C. Everaerts, Y. Roisin, J.L. Le Quere, O. Bonnard, J.M. Pasteels, J. Chem. Ecol. 19 (1993) 2865-2879.

[30] C. Sanz, D. Ansorena, J. Bello, C.C. Cid, J. Agric. Food Chem. 49(2001) 1364-1369.

[31] C. Varming, M.A. Petersen, L. Poll, J. Agric. Food Chem. 52 (2004) 1647-1652.

[32] C.H. Hwan, C.C. Chou, J. Sci. Food Agric. 79 (1999) 243-248.

[33] E. Fuhrmann, W. Grosch, Nahrung 46 (2002) 187-193.

[34] F. Bianchi, M. Careri, A. Mangia, M. Musci, J. Sep. Sci. 30 (2007) 563-572.

[35] H.A. Priestap, C.M. Van Baren, P. Di Leo Lira, J.D. Coussio, A.L. Bandoni, Phytochemistry 63 (2003) 221-225.

[36] H.S. Choi, J. Agric. Food Chem. 51 (2003) 2687-2692.

[37] I. Jerkovic, J. Mastelic, Phytochemistry 63 (2003) 109-113.

[38] J. Olivero, T. Gracia, P. Payares, R. Vivas, D. Diaz, E. Daza, P. Geerlings, J. Pharm. Sci. 86 (1997) 625-630.

[39] J. Piery, A. Pribela, J. Durcanska, P. Farkas, Food Chem. 54 (1995) 73-77.

[40] J. Ruther, J. Chromatogr. A 890 (2000) 313-319.

[41] K.H. Engel, R. Tressl, J. Agric. Food Chem. 31 (1983) 998

[42] L. Culleré, A. Escudero, J. Cacho, V. Ferreira, J. Agric. Food Chem. 52 (2004) $1653-1660$.

[43] N.P. Brunton, D.A. Cronin, F.J. Monahan, Flavour Fragr. J. 17 (2002) 327-334.

[44] N.W. Davies, J. Chromatogr. A 503 (1990) 1-24.

[45] O. Nishimura, J. Agric. Food Chem. 43 (1995) 2941-2945.

[46] P. Schnermann, P. Schieberle, J. Agric. Food Chem. 45 (1997) 867-872.

[47] P.K.C. Ong, T.E. Acree, J. Agric. Food Chem. 47 (1999) 665-670.

[48] R.G. Buttery, L.C. Ling, D.J. Stern, J. Agric. Food Chem. 45 (1997) 837-843.

[49] R.N. Kulkarni, G.R. Mallavarapu, K. Baskaran, S. Ramesh, S. Kumar, Flavour Fragr. J. 13 (1998) 389-392.

[50] R.P. Umano, Y. Hagi, T. Shibamoto, J. Agric. Food Chem. 50 (2002) 5355-5359.

[51] S.J. Lee, A.C. Noble, J. Agric. Food Chem. 51 (2003) 8036-8044.

[52] T.J. Bruce, A. Cork, J. Chem. Ecol. 27 (2001) 1119-1131.

[53] T.Y. Chung, J.P. Eiserich, T. Shibamoto, J. Agric. Food Chem. 41 (1993) 1693-1697.

[54] V. Ferreira, M. Aznar, R. López, J. Cacho, J. Agric. Food Chem. 49 (2001) 4818-4824.

[55] V. Galindo-Cuspinera, M.B. Lubran, S.A. Rankin, J. Agric. Food Chem. 50 (2002) 2010-2015.

[56] R Development Core Team, R: A Language and Environment for Statistical Computing, R Foundation for Statistical Computing, Vienna, Austria, 2009 (ISBN:3-900051-07-0, URL http://www.R-project.org).

[57] I.T. Jolliffe, Principal component analysis, 2nd ed., Springer, New York, 2002.

[58] D.A. Lambropoulou, T.A. Albanis, J. Chromatogr. A 922 (2001) 243-255.

[59] X. Yang, T. Peppard, J. Agric. Food Chem. 42 (1994) 1925-1930.

[60] N. Alizadeh, H. Zarabadipour, A. Mohammadi, Anal. Chim. Acta 605 (2009) 159-165.

[61] M.B. Melwanki, M. Fuh, J. Chromatogr. A 1198 (2008) 1-6.

[62] S. Zamúz, M. Vilanova, Flavour Fragr. J. 21 (2006) 743-748.

[63] J. Wenguang, F. Wenlai, X. Yan, Z. Guang'ao, L. Jiming, Y. Ying, Chin. J. Chromatogr. A 25 (2007) 881-886.

[64] M.R. Salinas, A. Zalacain, F. Pardo, G.L. Alonso, J. Agric. Food Chem. 52 (2004) 4821-4827.

[65] Y. Kotseridis, R. Baumes, J. Agric. Food Chem. 48 (2000) 400-406. 